\title{
Ending sex-based oppression: transitional pathways
}

\section{Holly Lawford-Smith}

\author{
[This is the final draft. The correct citation is: Lawford-Smith, Holly. 'Ending sex-based oppression: \\ transitional pathways', Philosophia (forthcoming).]
}

\begin{abstract}
From a radical feminist perspective, gender is a cage. Or to be more precise, it's two cages. If genders are cages, then surely we want to let people out. Being less constrained in our choices is something we all have reason to want: theorists in recent years have emphasized the importance of the capability to do and be many different things. At the very least, we should want an end to sex-based oppression. But what does this entail, when it comes to gender? In this paper, I'll compare four 'transitional pathways', with a view to considering how each relates to the ultimate end of ending sex-based oppression. Should we open the doors to the cages, so that people can move freely between them, but leave the cages themselves in place? (Transgender pathway). Should we add more cages? (Nonbinary pathway). Should we make the cages bigger, so that people have a lot more room to move around inside them? Or should we dismantle the cages, so there are no more genders at all? (Gender abolitionist pathways). Some of these options are 'gender revisionist', others are gender abolitionist. I'll argue in favour of a gender abolitionist pathway.
\end{abstract}

Keywords: sex-based oppression; gender; nonbinary; third gender; transgender; gender abolition; radical feminism; gender critical feminism; ideal theory; non-ideal theory.

\section{Gender norms}

From a radical feminist perspective, gender is a cage. ${ }^{1}$ Or to be more precise, it's two cages. The cages trap people with the biological sex 'male' and 'female' respectively. Those of the male sex are trapped by one set of gender norms - norms of masculinity - and those of the female sex are trapped by another - norms of femininity. ${ }^{2}$ Gender norms are social expectations about a person's behaviour applied to their sex.

Such expectations constrain the things that people can do and the ways that they can be, from who they date, how they present themselves, the way they move, the way they relate to other persons, the kinds of jobs they have, their passions and pursuits, the sports they play, and so on. For example, the gender norms applied to female people include androphilia (attraction to males), feminine presentation, contained movements, being warm and nurturing toward others, working in care- and people- focused jobs, pursuing e.g. dance or theatre rather than e.g. model-building or astronomy, playing e.g. netball rather than e.g. rugby, and so on.

Gender norms are one kind of social norm. Social norms are marked by the fact that conformity is dependent upon others' expectations. Non-conformity can be expected to bring social sanctions (Bicchieri 2016, pp. 35-40). The cage metaphor is appropriate, because gender norms are particularly heavily policed, relative to other kinds of social norms. When you push to the front of a queue, you may hear some muttering from those behind you; when you are a boy who wears girls' clothing, you may be harassed, verbally abused, and even physically assaulted.

It would be bad enough if these norms only pushed people into gender roles - the social roles resulting from a conformity to gender norms - that were 'equal but different'. But they do more than that; they push people into roles that are unequal. Men dominate, subordinate, and oppresses women. ${ }^{3}$ Femininity is constructed in a way that legitimates and facilitates sexual violence (MacKinnon 1987, pp. 85-92). Science is wheeled in to justify sex inequality (e.g. talk of gendered brains, or the difference testosterone makes - see discussion in Fine 2010; 2017), and violence and other forms of social policing work to maintain it (Manne 2017).

If genders are cages, then surely we want to let people out. Being less constrained in our choices is something we all have reason to want. Many normative theorists in recent years have emphasized the

\footnotetext{
${ }^{1}$ The aim of this paper is not to defend the conception of gender as norms against the alternatives (on which more in Section II), but to use one plausible conception of gender to explore the issue of ending sex-based oppression.

2 The cage metaphor will be familiar from Marilyn Frye's famous essay 'Oppression', in The Politics of Reality (1983), although she would likely resist my application of the metaphor to men, given that men are not oppressed (at least, not as a class).

${ }^{3}$ Some who make a sex/gender distinction of this type (sex/norms imposed on the basis of sex) also use the terms 'female' and 'male' to refer to sex, and 'woman' and 'man' to refer to gender. I don't think this is helpful, and will use 'female/woman' and 'male/man' as sex terms, and 'norms of femininity' and 'norms of masculinity' to refer to the gender norms.
} 
importance of the capability to do and be many different things (see e.g. Nussbaum 2011; 2000). At the very least, we should want an end to sex-based oppression. While female people are the largest group to benefit from an end to sex-based oppression, other groups benefit too, including gay, lesbian and bisexual people (because the gender norm of heterosexuality disappears); gender non-conforming people (because the gender norms of female people presenting in a feminine way and male people presenting in a masculine way disappears); and trans and nonbinary people (because if there are no gender norms, then there is no 'incongruence' between sexed bodies and gender expressions). But what is the best route to ending sex-based oppression?

Answering that question is the aim of this paper. I'll compare four 'transitional pathways' - from the world as it actually is to a world with substantially less, or no, sex-based oppression - with a view to considering how each relates to the ultimate end of eliminating sex-based oppression. Should we open the doors to the cages, so that people can move freely between them, but leave the cages themselves in place? Should we add more cages? Should we make the cages bigger, so that people have a lot more room to move around inside them? Or should we dismantle the cages, so there are no more gender norms at all?

These are questions in non-ideal theory, about the pathways from the actual world as it is currently, where genders are cages, to the ideal world, whether that is gender abolitionist or merely gender revisionist (for a useful overview of ideal and non-ideal theory, see Valentini 2012). But because ideal worlds include their histories, the question of which pathway to take is crucial to establishing which is the ideal world. It also helps to make clear that the gender abolitionist pathway is high ambition, leading to liberation for many more people, while the gender revisionist pathways, particularly the nonbinary pathway, are low ambition, leading only to minor changes to the status quo.

This discussion should be of interest to radical and gender critical feminists (and their allies) committed to gender abolitionism; to transgender people (and their allies) committed to revision of the existing gender binary without abolishment; to nonbinary people (and their allies) committed to resisting the gender binary; and indeed to all gender-conforming and gender non-conforming people who have thought about possible tensions between sex-based oppression and identities that depend on the existence of gender norms in some form or other.

\section{A world without sex-based oppression, and transitional pathways}

Let's return to the metaphor of gender as two cages. It's easy enough to imagine ways to make things better. Here are four possibilities, some of which I've already mentioned:

(1) Open the cage doors

(2) Add a new cage

(3) Add escape hatches to the cages

(4) Make the cages bigger

A world where the cage doors are open would be better, because then at least people would have a choice about which cage to be in. They could choose to move from the one cage to the other, and perhaps even to move freely between them. In the world where gender is two cages but the cage doors are open, sex and femininity/masculinity will have been fully decoupled. At the moment to be female is to be put in the 'feminine' cage; in a world with open cage doors, a female person would get the choice whether to be put in the 'feminine' cage or the 'masculine' cage.

A world where there's an additional cage, which people from either of the two other cages are free to enter, would also be better, because again this would give them a choice about which cage to be in. In principle one could add in any number here, although at a certain point, the question of whether these additional cages are still gender, rather than e.g. personality, will emerge. At the moment to be male is to be put in the 'masculine' cage; in a world with a third cage, the male could opt out of the cage of 'masculinity' and into the new cage.

A world where the cages had escape hatches would also be better, because then anyone who wasn't comfortable in the cage they were in could leave it. This gives some people more freedom, and it transforms the status of the cages: if it's viable for everyone to take the escape hatch, and people choose to remain in the cage of their own volition, they are not accurately described as 'trapped' or 'constrained' or 'imprisoned'. The cages become mere options. 
A world where the cage doors remain shut but the cages are bigger would also be better, because there would be fewer constraints on the ways that people of a particular sex could be, or the the things that people of a particular sex could do. The bigger the cage, the more ways there are of being a man, or a woman. There may be as many ways - or more - of being a man as there are men; as many ways or more - of being a woman as there are women. If there are many ways to be a woman, but they overlap either not at all, or only in part, with the ways there are to be a man, and vice versa, then there's a lot more freedom, but there are still gender norms.

There are versions of (3) and (4) which amount to the same thing: getting rid of the cages entirely. If everyone takes the escape hatch then no one is caged, and if it's viable for everyone to take it then some people remain in the cage but are not technically 'caged' (because they are free to leave). If the two cages become so big that they overlap perfectly, then being caged is equivalent to not being caged. (Building a wall around the whole world wouldn't make it a prison). The ways of being a woman would overlap perfectly with the ways of being a man. A world where there are simply no cages would be better than the world where there are two but it's possible for some to escape, and the world where there are cages that are bigger (less constraining) than they are now, but still constraining. No cages at all means maximal freedom: male and female people are free to do and be whatever they want to be. The world without cages achieves the radical feminist goal of gender abolitionism (sometimes also called 'gender annihilation') (see e.g. Atkinson 1974, pp. 42-43; Firestone 1970, pp. 184-187; Frye 1983, pp. 35-37; The Feminists [1969]).

So we have four transitional pathways, all of which would take us to a world that is better than the actual world, at least when it comes to sex-based oppression. We don't yet know which of these would be the best pathway. So long as the best pathway is accessible to us, we should take it (if it were inaccessible, and we knew that, then we would be justified in taking another). One way we can start to think about which is the best is by thinking about the tradeoffs each pathway involves compared against the others.

Before I get onto that, let me note emphatically that nothing I say below is intended as a criticism of current gender norm-violating (or 'gender non-conforming') people. This is a speculative paper about pathways to a world without sex-based oppression, and its observations depend on substantial numbers of people taking up the proposed strategies. In the actual world, people have their own reasons for violating gender norms, including being gay, being transgender or nonbinary, ${ }^{4}$ alleviating gender dysphoria, alleviating discomfort with aspects of one's physical sex, expressing opposition to gender norms, or to 'the gender binary' (on the latter see Dembroff 2018), and selfexpression.

Most of these reasons would not be undermined by a philosophical discussion concluding that widespread adoption of transgender, third gender, or nonbinary identities is not the best pathway to a world without sex-based oppression. (The political reasons, however, would be undermined.) But all such reasons might be bolstered by a philosophical discussion concluding that transgender, third gender, or nonbinary identities are part of the best pathway. (Wouldn't it be satisfying for a gender identity activist to be able to say to a so-called 'trans-exclusionary' radical feminist, 'I'm doing my part in bringing about the world that you want?')

To translate the metaphorical cages into real strategies for political change, we have: changing between the two genders ('transgender pathway'); opting into a third (fourth, etc.) gender category ('third gender pathway'); 5 opting out of binary gender ('nonbinary pathway') without opting into a third gender category; and rejecting gender without repudiating being a female/woman, or male/man ('gender abolition pathway'). Which of these is the best transitional pathway to the world without sex-based oppression? Here is the list, so we can keep track:

(1) Open the cage doors $\rightarrow$ Transgender pathway

(2) Add a new cage $\rightarrow$ Third gender pathway

\footnotetext{
4 'Transgender' is usually used as the umbrella term, which includes both trans and nonbinary identities underneath it. I find it conceptually unhelpful to have an umbrella term that is also the term for one of the identities it covers, so I'll simply stipulate usage: 'transgender' in my usage means a person born male who identifies as either or both of female/woman, or a person born female who identifies as either or both of male/man. 'Nonbinary' in my usage means a person of either sex who identifies as neither a woman or a man.

${ }^{5}$ I'll use 'third' in the rest of the paper, but this should be taken to mean any number of genders greater than two.
} 
(3) Add escape hatches to the cages $\rightarrow$ Nonbinary pathway

(4) Make the cages bigger $\rightarrow$ Gender abolition pathway

What are the 'limit cases' for each pathway? I'll assume that for the transgender pathway, it is when half of all female people are subjected to norms of masculinity, and half of all male people are subject to the norms of femininity. ${ }^{6}$ For the third gender pathway it is when there are sufficiently many gender categories that no one feels trapped, and membership in these categories is freely chosen. For the nonbinary pathway, it is when everyone has repudiated being either female/women or male/men, so there are no people left for gender norms to be applied to. For the gender abolition pathway, it is when no one has repudiated being female/women or male/men, and yet gender norms are not applied to anyone. We would expect to see the full spectrum of the behaviour that has historically been gendered, not clustered any longer according to sex.

The pathways introduced above are not mutually exclusive. In the actual world, they are all in play. But as political strategies to end sex-based oppression, they will be most effective if there is momentum around one in particular. That is because if the non-binary pathway is successful it pulls the rug out from under the transgender pathway; if the transgender pathway is successful it precludes the gender abolition pathway. (Still, in Section 3 I will briefly consider hybrid pathways). Each pathway comes with costs, and these costs impact upon different groups.

I think that these differential costs partly explain some of the heat around debates over proposed (and in some cases actual) changes to the recognition of sex/gender under the law, for example the 2018 consultation over the Gender Recognition Act (2004) in the UK, debate over the Human Rights (Gender Identity) Amendment Bill in New Zealand in 2019, and the quiet passing of the Births Deaths and Marriages Registration Amendment Act (2019) in Victoria, Australia in 2019.7 Gender critical feminists have argued that there's a tension, brought out by these proposed (and actual) legal changes, between advancing the interests of transgender, third gender, and nonbinary people, on the one hand, and advancing the interests of females/women on the other (Burt 2020; Asteriti \& Bull 2020; Murray \& Hunter-Blackburn, 2019; Stock 2018a; 2018b; Reilly-Cooper 2016a; Lawford-Smith 2019a; 2019b; 2019c). Comparing these differential costs can help in figuring out which is the best pathway to escape sex-based oppression.

I'll take them in reverse order, starting with the gender abolition pathway, then moving on to the nonbinary pathway, the third gender pathway, and finally the transgender pathway. The gender abolition pathway is, as its name suggests, gender abolitionist, while the nonbinary, third gender, and transgender pathways are merely gender revisionist. This means that in assessing them, we have to think not only about what gender is, but what gender should be (if anything at all).

\section{i. The gender abolition pathway}

Along the gender abolition pathway, no one repudiates their sex. No female/woman claims that she is not female/woman, and no male/man claims that he is not male/man. But everyone repudiates their gender, understood as the set of norms they are subject to on the basis of their sex (masculinity for males/men, femininity for females/women). People do whatever they like, which means many women violate the norms of femininity and many men violate the norms of masculinity. This not require that everyone violate all such norms. Feminine is a way to be female just as much as it is a way to be male, and the same is true for masculinity. So there will remain some feminine women and some masculine men. But these combinations will not be seen as normative. At the 'end' of this pathway, when we map the full spectrum of human behaviour, we will find that it does not cluster in significant ways according to sex.

This does not require accepting a 'blank slate' view, presuming that in the debate over nature/nurture/nature via nurture the correct diagnosis of all sex differences is 'nurture'. It requires only to say that whatever proportion of 'femininity' and 'masculinity' have been constructed through early

\footnotetext{
${ }^{6}$ R.A Briggs \& B.R George make a similar assumption when they explore the 'liberalisation' of gender categories on trans twin earth: 'Through all these changes the [gender] roles themselves remain largely intact, but the demographics of the two worlds shift until there is no correlation at all between gender role and biological sex characteristics. [...] roughly half of all blokes and half of all grrrls possess typically female biology' (Briggs \& George manuscript., p. 18). ('Blokes' is the name they give to the previously male-associated gender category, 'grrrls' to the previously female-associated category).

7 The latter, which came into force in May 2020, makes legal sex a matter of statutorily declared belief.
} 
childhood socialisation, culture, and social sanctions/rewards, that will disappear - and the interests previously gendered will be distributed more evenly across the population. This is compatible with there remaining some interests that relate more directly to sex, for example things to do with reproductive function, the specifics of sexed bodies, and sexual orientation / attraction. ${ }^{8}$

So far this is just the familiar feminist distinction between sex and gender, ${ }^{9}$ where we get rid of gender by getting rid of sexist assumptions about how sexed persons should be and what they should do. It is distinctive because of its focus on ways of doing and being, rather than on identity labels. By violating gender norms, it hopes to erode and dismantle those norms, to leave people to be however they would be without them.

Which social groups does the gender abolition pathway involves costs for? Understanding this will allow us to assess the desirability of the pathway on its own merits, and then later to make tradeoffs between the four pathways. The first group who there are costs for will be those who wish to repudiate their sex. Because the violation of gender norms must be undertaken without repudiation of sex class membership, we'll need to know how many of the people who currently repudiate their sex would still want to do that when their sex did not constrain them in any way. All those who are transgender, nonbinary, or third gender because of a gender dysphoria that is specifically about their bodies are likely to still want to opt-out of their sex class.

Those who are transgender, nonbinary, or third gender for purely political reasons (or social reasons, or other kinds of voluntary reasons) are not likely to still want to opt out of their sex class. It strikes me as plausible - although it's ultimately an empirical question - that the wider the scope of what it means to be a female person, or a male person, the less people would feel the need to repudiate their sex.

This is a point that many people critical of surgical transitioning (the undergoing of sex reassignment surgery) have made: we should change society so that it's more accommodating of difference, rather than change physically healthy individuals so that they can fit into the other of the small cages society currently has to offer (see e.g. discussion in Raymond 1979). (Again, this is not intended as a criticism of people who undergo such surgery; it's intended as a criticism of gender norms, and the extent to which such people may not feel the need to have surgery if we managed to dissolve those norms).

This pathway will also be costly for transgender people who feel strongly that they are, or ought to be, subject to the gender norms of the other sex. Here's transwoman Andrea Long Chu, in an interview with Anastasia Berg for The Point Magazine:

'The TERF position that I would through transition be solidifying and reproducing normative gender rolesI find that argument completely convincing. I mean I think it's completely right, because I know that it's right, because it's the thing that I want! Like, I'm not interested, actually, not at all interested in dismantling gender' (Long Chu \& Berg 2018).10

Normative gender roles are built out of conformity to gender norms, so there cannot be roles without norms. The fulfillment of Long Chu's desires depends on gender norms. So the abolition of gender frustrates those desires.

Costs to a third social group depend on the implications, in the early stages of the pathway, of others' violation of gender norms. Consider two female people, and imagine that one conforms to gender norms while the other violates gender norms without denying her membership in the class to whom the norms apply. The fact that the second violates gender norms may be taken to imply that those who conform to gender norms accept their subjection to gender norms. But they may not; they may conform because they cannot afford the sanctions of non-conformity; they may conform because they happen to prefer to be as the norms direct them to be, while wishing there were no such norms.

\footnotetext{
8 As Marilyn Frye put it: 'we do not know whether human behaviour patterns would be dimorphic along lines of chromosomal sex if we were not threatened and bullied; nor do we know, if we assume that they would be dimorphous, what they would be, that is, what constellations of traits and tendencies would fall out along that genetic line' (Frye 1983, p. 36).

${ }^{9}$ Cf. Bogardus 2020 on whether there really is such a distinction.

10 Note: the term 'TERF' is used by gender identity activists to refer to radical feminists, '- RF', who acknowledge transwomen to be male and thus justifiably excludable from female-only spaces. The 'TE - ' stands for 'trans-exclusionary'. Radical feminists do not self-describe with this term, and many consider it to be a slur. See discussion in Allen et al. manuscript.
} 
Given that these costs relate only to a person's actions being interpreted correctly by others, I give them little (but not no) weight (cf. Jenkins 2018, p. 732).

The gender abolition pathway comes with costs for one final social group: those social conservatives who think that there are many natural differences between men and women, that conformity to gender norms is morally good, and that the gender roles that result from conformity to gender norms structure society in a positive and meaningful way.

In 1963, Helen Andelin wrote Fascinating Womanhood, directing women to be good wives to their husbands by reverting to traditional gender roles. She advocated 'girlishness, tenderness, and sweetness of character', and advised letting 'him be the guide, protector, and provider' (Smith 2017; see also Neuffer 2015 \& Andelin 1963). There are conservative women (and indeed, some liberal women too) who enjoy gender role differentiation within a heterosexual relationship, and do not feel all gender norms to be constraining (e.g. they may be happy enough to be expected to be homemakers while their husbands work, even if they would rather not be expected to respond positively to catcalling).

It is tempting, of course, to dismiss these beliefs as adaptive: 'traditional husbands' have become accustomed to their privilege and 'traditional wives' have become resigned to their subordination. But it's dangerous territory to start assuming the ability to distinguish adaptive from non-adaptive beliefs (such distinctions are sometimes warranted, but they should be used sparingly). Any social change that will reduce the wellbeing of a particular social group should be factored in. So this cost counts.

In summary, there are four social groups for whom the gender abolition pathway comes with a cost. These are (i) the transgender, third gender, and nonbinary people who would still want to opt out of their sex class even when that sex class came with no particular expectations; (ii) the transgender people whose identities depend upon the existence of gender norms; (iii) those at the early stages of the pathway who do not violate gender norms; and (iv) the gender traditionalists, who would be unhappy to lose the sense of purpose, and social scaffolding, that comes from gender norms and the roles that come from conformity. For everyone else, the gender abolition pathway is liberating.

How do these internal costs and benefits pan out? While the costs to the transgender, third gender, and nonbinary people in (i) and the transgender people in (ii) are high, both groups are very small; ${ }^{11}$ and while the group of those who are not gender norm-violating early on is large, the costs to individuals in that group are minimal. The costs to gender traditionalists may appear to be high; after all, they are a large group, so this pathway may risk a substantial loss of wellbeing. But this risk is partly mitigated when we remember that gender abolition means gender norms not being applied to anyone. That doesn't mean there can be no femininity (or masculinity), only that there can be no enforcing of femininity onto females (masculinity onto males). Those of the gender traditionalists whose preferences remained firmly in place even as social incentives around presentation, behaviour, and roles changed would be free to remain as they were. Thus the loss of wellbeing is not individual, about any particular woman having to do other than she prefers, but social, about the fact that she can no longer conceive herself as fulfilling a woman's destiny, or doing what women ought to do. Abolishing gender means there is no such thing. But it is not clear how much wellbeing there is in that.

The remaining group of people for whom this pathway would be liberating (which includes those who are norm-conforming in the early stage) is extremely large. Women, who stand to benefit the most from gender abolition (although men will benefit too), make up roughly half the population. (And this includes gender traditionalist women, who will benefit in other ways). Once we add in gay and bisexual men, and other gender non-conforming men, all of whom will benefit from gender abolition too, we have an even bigger group. So unless the interests of gender norm-dependent trans people or gender traditionalists are so important as to be considered to trump the interests of everyone else, there are no internal

\footnotetext{
11 The closest group to (i) for which there is a population estimate is transsexuals, people who have had sex reassignment surgery. On one estimate, there were between 2,400 and 10,500 transsexual people in the UK (Equality and Human Rights Commission 2009, p. 33). The total population of the UK in that year was 62 million, which means transsexual people were less than $0.02 \%$ of the population. The closest group to (ii) for which there is a population estimate is what the UK Equality and Human Rights Commission calls 'the trans population'. This will be an overestimate relative to the understanding of transgender stipulated in fn. 4, because it will count nonbinary people, and other people too (see discussion in ibid, pp. 10-19). The estimated size of the trans population in the UK was between 65,000 and 300,000 (ibid, p. 33). That is $0.48 \%$ of the population.
} 
reasons not to pursue the norm-violation pathway. (The comparison between the four pathways must be left until the end of this section).

\section{ii. The nonbinary pathway}

One straightforward way to understand the difference between the gender abolition pathway and the nonbinary pathway is the matter of how to violate gender norms. According to the gender abolition strategy, no female person denies that she is female/woman, but she might violate the norms of femininity. According to the nonbinary strategy, nonbinary people $d o$ deny that they are female/women (in the actual world, there is diversity among nonbinary people in which of these, if any, is denied). Whether or not they also violate other gender norms, this denial of sex/gender category is front and centre in the nonbinary strategy.

On the radical feminist understanding of gender, where gender is a set of norms applied on the basis of sex, it is hard to understand what the point of denying these categorisations would be. There is a fact of the matter about a person's sex, and there is a fact of the matter about which set of norms they are subjected to on the basis of that sex (with some exceptions for people who are perceived by others to be the opposite sex). Is the political strategy here to simply deny facts?

We can avoid this conclusion by shifting to an alternative conception of gender, rather than insisting that gender is (only) norms. The term 'gender' is polysemous, at least in the academic literature if not beyond. It might refer to any of 'gender role, gender identity, gender expression' (Barnes 2020, p. 20), ${ }^{12}$ gendered social position (ibid, p. 13), or as we have been discussing, gender norms. If we take gender to be gender expression, then androgynous or masculine -presenting female nonbinary people may claim to 'escape the cage' of (binary) gender by expressing themselves in non-feminine ways. (Still, they would have to answer the question of why they are not female/women, while other androgynous or masculine -presenting female people are; or, alternatively, bite the bullet on a lot of women being mistaken that they are female/women).

The two main 'types' of theory of gender are social position theories, and identity theories (Barnes forthcoming, pp. 3-10 \& exceptions in fn. 11). Social position theories are 'externalist'. They take gender to be a position in a social structure, a matter of how others perceive you, treat you, expect you to behave, etc. (see e.g. Ásta 2011, 2019; Witt 2011; Haslanger 2012; and discussion in Barnes 2020). Identity theories are 'internalist'. They take gender to be a matter of how you feel, how you see yourself, which group you take yourself to belong to (see e.g. Appiah 1990; McKitrick 2015, Bettcher 2009, 2013; Jenkins 2016; 2018; and discussion in Barnes 2020). The radical feminist view of gender as norms is externalist; perhaps an internalist view would make better sense of the nonbinary strategy?

While proponents of gender identity theories have accused externalist social position theorists of having an exclusion problem (specifically, failing to include transwomen as women), gender identity theories face an exclusion problem of their own (specifically, failing to include some natal women as women) (Barnes 2020). The most worked-out theory of gender identity on offer actually understands gender identity as taking norms to apply to you, for example, a male person has the gender identity 'female/woman' when he takes more of the norms applied to female people to apply to him than the norms applied to male people (Jenkins 2018, pp. 728-736, esp. p. 731). That means gender as gender identity depends on a prior understanding of gender as gender norms.

But Jenkins' account fails on the grounds that this is not how norms work. Others apply norms to you, and sanction you for non-conformity. You can take norms to apply to you all you like, but if you won't be sanctioned for non-conformity, then you're simply making a mistake. Most people with gender identities will be subjected to the norms applied to people of their sex (there are some exceptions for people of one sex who are perceived by others to be the opposite sex). So internalist theories are largely unpersuasive. They have going for them that they are 'inclusive' and vindicate the self-understandings of some people who are marginalized. But they have against them that they capture virtually nothing of the empirical fact of sex-based oppression, and offer little contribution to dismantling it.

Returning to the externalist understanding of gender as norms, then, can we understand the nonbinary strategy as a version of the gender abolition strategy focused specifically on rejecting the norm that everyone is either a male/man or a female/woman? Nonbinary people attempt to escape gender norms by denying that those norms are correctly applied to them. Robin Dembroff, who is

12 Page references refer to the early view version of the paper: https://philpapers.org/rec/BARGAG-6 
nonbinary, insists that this need not involve denial of one's sex or gendered socialisation, writing 'most nonbinary persons do not claim they are (or were) not marked with a binary sex, or socialised according to that assigned sex. Whatever these persons mean by claiming nonbinary identities, it is not a lack of gendered socialisation' (Dembroff 2018).

Terminological differences lead to the appearance of a more disagreement than there really is between the gender abolition strategy and the nonbinary strategy, I think. Radical feminists tend to refer to the gender norms as 'masculinity' and 'femininity'. On this view, a female person who violates gender norms may not be feminine, but she is still a woman. But some refer to the social role of those to whom gender norms are (successfully) applied as 'woman' and 'man', so a female person who violates gender norms is not a 'woman'. If we use the latter terminology, then we can accept Dembroff's point that nonbinary people need not deny their sex or sexed socialisation, compatible with the point that they protest gender by denying that they are women, or that they are men. ${ }^{13}$

But there isn't any real difference here. Nonbinary people are just male and female people who oppose the application of gender norms to sexed beings (or at least, to themselves). They attempt to sidestep the application of gender norms by sidestepping sex/gender classification.

If what it is to be 'neither a male/man nor a female/woman' is to be a third gender, then the nonbinary strategy is a version of the third gender pathway. If it is no gender, or a rejection of gender, then it is a version of the gender abolition pathway. In either case, it remains distinctive, because of the way it articulates that third gender, or the specific kind of norm violation it focuses on.

There is a question about the likely efficacy of this pathway. There really are gender norms, and they really are applied on the basis of sex. So unless nonbinary people successfully confound sex classification, it is unlikely that they would escape subjection to gender norms. A child bride cannot escape being married off to a life of domestic and sexual servitude by claiming that she is neither a woman nor a man. So there is a risk that this pathway actually does little to challenge the status quo. That creates a large group for whom there are high costs: all the people suffering sex-based oppression that have been mentioned already.

If nonbinary people do not confound sex classification, but violate the gender norms applied to people of their sex in other ways, then they will be advancing the gender abolition project (through nonconformity) rather than the specifically non-binary project (through increasing the size of the group of people not subject to either set of gender norms). If nonbinary people $d o$ confound sex classification, there is a risk of new norms evolving for the policing of nonbinary as a third gender category, rather than no gender. So they themselves are the second group for whom this pathway may involve costs.

Which other social groups are harmed by the nonbinary strategy? In the early stages of the pathway, before it reaches its conceptual limit, the nonbinary strategy involves costs for those people who do not deny that they are female/women or male/men. Consider two female people, one who conforms to feminine gender norms and doesn't claim to be nonbinary, and another who violates feminine gender norms by denying that they apply to her, because she is nonbinary. The fact that the second denies the norms apply to her may suggest they $d o$ apply to the woman who does not claim to be nonbinary, and thereby reinforce feminine gender norms for other women (Reilly-Cooper 2016b; Cox 2016; cf. Skylar 2016). This is a comparative cost: in a straightforward choice between being a female/woman astrophysicist, and being a nonbinary astrophysicist, the former does more to challenge gender norms and contribute to the dismantling of sex-based oppression than the latter. The former is a positive representation of a woman doing something that is atypical for women; the latter leaves women to their feminine jobs and casts an astrophysicist as 'not a woman'.

At the end of the pathway, as mentioned already in $i$., there are also costs for anyone who liked the sex/gender binary and doesn't want a world of nonbinary humans. This includes the gender traditionalists and the transgender people who depended upon the gender norms (i.e. who wanted to swap categories, not for the categories to be eliminated). Given the risk of inefficacy, the size and seriousness of the potential harms, and the fact that nonbinary people who don't confound sex

\footnotetext{
13 It has been common in recent feminist history to take this view, that 'man' and 'woman' refer to social roles. But this creates a contradiction with ordinary linguistic usage, in implying that all female people who don't occupy the social role don't count as 'women' (for a discussion about the ordinary understanding of 'woman' see Byrne forthcoming). On the understanding of gender as gender norms, a female nonbinary person is a woman, because (or, as long as) the norms of femininity that are applied to female people are still applied to her. For an argument against 'woman' as a social role, see Stock, manuscript.
} 
classification will actually be contribution to the gender abolition pathway, the nonbinary pathway doesn't look to have a lot going for it.

\section{iii. The third gender pathway}

Along this pathway, increasing numbers of male and female people start declaring themselves to be members of third gender categories. This means more freedom: the more gender categories there are the more choice people have, and the less constrained they are.

There are already third gender categories in many countries, including Australia (among Aboriginal people), Samoa, India, Pakistan, and the United States (among Native Americans). Some people already conceive of gender as a 'spectrum', which contains as many categories as there are personalities (for criticism see Reilly-Cooper 2016b).

One advantage of this pathway compared to the transgender pathway - yet to be discussedis that it avoids a conflict between transwomen and women. When we add genders, people can opt out of one of the traditional two without that entailing they must opt into the other. When we merely liberalise membership of the two traditional gender categories, a male person's opting out of maleness, manhood, masculinity means his opting into femaleness, womanhood, femininity. For those female people who have been subordinated by male people on the basis of their sex, this can seem a bitter pill to swallow - at least if it means accepting such people in female-only spaces, as mothers, as lesbians, etc. The third gender pathway sidesteps such conflicts.

One problem with this pathway is the same as that raised already for nonbinary people, which is that if gender norms are applied on the basis of sex, and it's difficult to confound sex classification, then this pathway won't actually result in an escape from gender, at least not in the sense I'm understanding it in this paper. If we take this pathway, we might still end up in a world with oppressive social norms applied on the basis of a person's sex. That means there's a serious cost for all people who are oppressed on the basis of their sex, i.e. all female people, because this pathway does nothing to mitigate their oppression.

I said earlier that the third gender pathway and the transgender pathway were merely gender revisionist. At this point it matters a lot how revisionary they are.

If the gender norms applied to a person on the basis of her sex are the same as they are now, regardless of the proliferation of new gender categories, then we still have sex-based oppression, and this world is not better than the one we are in now. (The 'pathway' to the ideal is no pathway at all). If, however, the gender norms applied to a person on the basis of her sex are replaced by norms applied to a person on the basis of her third gender class membership, and there are many such classes membership in which is freely chosen, then there may be little or no sex-based oppression at all.

This pathway comes with costs for transgender people who do not see themselves as 'third gender', but rather as one of the existing two genders. If third gender categories translate into third gender spaces, this may be felt as a further cost by people who society classifies as third gender but who would themselves prefer to use the spaces of one of the existing two genders. It also comes with costs for anyone who would still feel constrained by the gender categories, no matter the options. (Imagine that there are three gender categories, and a person feels that none fit her; imagine there are twenty categories, and a person feels that none fit her).

It's difficult to assess the internal tradeoffs here, because much depends on whether binary gender norms (norms that apply to sex class membership) are replaced at some point along the pathway by third gender norms (norms that apply to membership in one of the new plurality of classes).

In terms of the costs to transgender people the tradeoff is the same as for $i$., namely that while the costs are high, the number of people affected is small, so unless their interests trump everyone else's, there are no internal reasons not to pursue the third gender pathway. Because this pathway comes with a risk of failing to mitigate sex-based oppression while the gender abolition pathway doesn't, the gender abolition pathway looks to be ahead in terms of overall cost-benefit tradeoffs.

$i v$. The transgender pathway

Along the transgender pathway, increasing numbers of male people start being subjected to the norms of femininity, and increasing numbers of female people start being subjected to the norms of 
masculinity. ${ }^{14}$ It's important to make a distinction here between conforming to norms that are applied to you, and acting in a way that is congruent with the norms that are applied to others. On my conception of gender, specific norms are applied to the members of the female sex class. If a person is a member of the male sex class, but either chooses or feels compelled to act in a way congruent with the norms applied to the members of the female sex class, that does not mean he shares a gender with female people. Gender is subjection to specific norms, whether you conform to those norms or not. ${ }^{15}$

Some people who are transgender change some of their primary sex characteristics (via sex reassignment surgery) or secondary sex characteristics (via hormone replacement therapy) so that they may be perceived by others as members of the sex class to which the norms are applied. Such people may more accurately be said to 'conform' to the norms rather than simply act in a way congruent with the norms. People who are transgender but choose not to take steps (or are unsuccessful in the steps they do take) to be perceived by others as members of the sex class to which the norms are applied merely act in a way congruent with the norms. For the transgender pathway to be a pathway at all, it will need to be that people conform to the norms of the opposite sex class, not merely act consonantly with them. (Otherwise there is no challenge to gender, because there is no shift in the makeup of the population to which the norms are applied).

Transgender author Julia Serano (2007) argues that transgender activism is a feminist movement. For Serano, the problem we have with gender, as a society, is not that gender roles oppress those who occupy them, but that femininity is constantly devalued relative to masculinity. On this view, to remove much, if not all, gender injustice, we need to do two things. The first is to decouple sex and gender (which on my understanding would mean making it the case that people can choose which set of norms applies to them). This removes one major constraint, which is that one's gender is not chosen. The second is to improve the status of femininity, pushing against 'the belief that maleness and masculinity are superior to femaleness and femininity' (Serano 2007; see also Pandian 2018). This maintains the two traditional gender categories, but it equalizes them and gives people a choice.

At the end of this pathway, we have the same gender categories - masculine and feminine (or what some others call 'man' and 'woman') - but they are composed differently in terms of sex, with male and female in each, and they are valued equally. This is unlike the end of the gender abolition pathway and the nonbinary pathway, where there will be no genders. (For the former, there will be female/women and male/men but no gender; for the latter there will be female and male but no gender - in the sense that if everyone is nonbinary then no one is). And it is unlike the end of the third gender pathway, where there will be sexes and many different genders.

Which social groups does the transgender pathway involve costs for? It comes with serious costs for female people, at least in the beginning of the shift. We currently live in a sexist and misogynistic society, where men have advantage over women, and women have disadvantage relative to men and suffer violence at the hands of men. If we want to get to a society without sex hierarchy, we need to mitigate the historical oppression of women and women's ongoing disadvantage, and that means keeping track of who has in the past suffered sex-based oppression, and who continues to suffer sex-based disadvantage. In a society in which people of either sex identify into and out of each other's categories, it will be hard to keep track of sex-based privilege and oppression. At least, this will be true if the law fails to keep track of 'original' sex class membership after sex class membership has been liberalised. (This problem is in large part an artifact of many countries' failure to keep sex and gender separate in the law - working to protect transgender rights by replacing sex with gender identity, rather than adding distinct protections for gender identity or gender expression).

Consider an analogy: a person who lives in a racist society pronounces herself to be 'colourblind'. That is, she says she doesn't see race, she just sees people. That's all very well, we might tell her, but if you don't see race then you don't see racism, and that means you're not able to do anything

\footnotetext{
${ }^{14}$ Note that because the numbers of people with gender dysphoria are too small to make this pathway successful, we have to imagine people without gender dysphoria nonetheless taking it up.

15 If we understood this pathway in a weaker way as requiring only action congruent with gender norms, it would seem to become a version of the gender abolition pathway - people of each sex violating gender norms by acting in accordance with the other sex's norms. The problem with how that is working in the actual world is that by claiming to actually be the opposite sex/gender, the behaviour is not necessarily interpreted as norm-violating.
} 
to help its victims. We don't want colourblindness in a racist society, because we want to be able to mitigate racist oppression, in order to eventually get to a non-racist society.

Ditto for sex-blindness in a sexist and misogynistic society. By the time each gender class is occupied by $50 \%$ female and $50 \%$ male people, it will be impossible to make provisions for the amelioration of sex-based oppression - or at least, not without catching a whole lot of people who don't need it, and missing a number of people that do. But there will be a lot of unfairness along the pathway if we lose the ability to recognize, and therefore mitigate, the historical and ongoing oppression and disadvantage of female people.

In case this seems like a merely hypothetical worry, note that in the UK, transwomen have taken positions on political party shortlists reserved for women as an attempt to improve women's participation in politics; in the US, Australia, and New Zealand, transwomen have competed in and won at women's elite sports; in the UK, a transwoman was invited to speak at a women's film festival, put together to work against the exclusion of women from the film industry; and so on.

This might seem like a strange thing to articulate as a cost. There are many differences within the class of women: black women, brown women, white women; poor women, rich women; lesbian women, bisexual women, straight women; able-bodied women, disabled women; neurotypical women, neuro-atypical women; young women, old women; and so on. If positions reserved for women (as a measure to combat historical injustice against women by men and equalise relations between the sexes) were filled with white, rich, straight, able-bodied, neurotypical, cis women, other women could complain, because these are the most privileged of the class of women. If such positions were filled with black, lesbian, disabled women, no one could complain, because they're not a privileged group within the class. This is why it's so important to consider the intersection of different identities (Crenshaw 1989). But transwomen are not a privileged group within the class, so why isn't that analogous?

Bracketing for the sake of argument the more controversial question of whether they are appropriately understood as a group within the class at all, there's an interesting question about whether we should expect to see them become the privileged group within the class once the sex composition of the class has changed. Transwomen who are assumed by others to be female, but in the past were assumed by others to be male, will have the historical advantage of male socialisation and the future disadvantages of being treated as female. (Gendered socialization is influential, and much of the conditioning effect that it has will be invisible to its subjects. This undermines the claim sometimes made that people who experience gender dysphoria will simply reject their gender socialization - see e.g. Finlayson et al. 2018).

Transwomen who were in the past, and continue to be, assumed by others to be male (i.e. are consistently 'misgendered') will have historical male privilege and future male privilege (which is compatible with their also being disadvantaged in virtue of being trans people, which is a distinct, and significant, cause of disadvantage). To the extent that some transwomen will have experienced male socialization, we should actually expect to see them come to be privileged within the class, because males are socialized to be bold, ambitious, dominant, self-confident, etc. (This point about the 'male privilege' that many transwomen have is acknowledged in the 'The Transfeminist Manifesto' - see discussion in Koyama 2011). This is something that we should take seriously as a cost to women, not because it's bad for one type of woman ${ }^{16}$ to be dominant (although it is), but because males are already so dominant outside the class.

One response here is to emphasize the fact that these costs only arise if the shift between gender categories is accompanied by a shift between legal sex categories. If it isn't, and sex continues to be a legally protected characteristic, ${ }^{17}$ then we could continue to track the oppressed group by tracking the female sex rather than the female gender, at least until such a time as the gender revolution is complete and sex-based oppression has disappeared. This will still mean making some mistakes, because trans men will count as female but may lose status as oppressed the longer they spend being assumed by others to be male, and symmetrically, transwomen will count as male but may lose status as privileged the

\footnotetext{
16 Note that this is a revised understanding of 'woman' as a class for the purposes of discussion in this section, and is at odds with the usage synonymous with 'female' used throughout the rest of the paper.

17 Or sex and gender could be legally protected characteristics (as they are in the UK, where a person can get a Gender Recognition Certificate, but there are specific exemptions for where sex and recognized gender come apart). In this case there would be need to be clear guidelines allowing the exclusion of all male people from female-specific rights and legal protections regardless of gender.
} 
longer they spend being assumed by others to be female. But these mistakes involve smaller numbers of people.

This comes with the implication that we should apply very strict conditions to a person's changing their legal sex - for example, we might want to make this impossible, or at the very least keep legal records of birth sex - which will count as yet another cost for people in the trans community who want to change their sex on official documentation and not just change their gender class membership. If sex continues to be legally protected, and the protection of gender class membership - on a conception of gender that is not 'the norms applied on the basis of sex', obviously - is kept distinct, then the conflict of interest between transwomen and women is largely resolved.

This pathway is extremely costly for everyone who would prefer to challenge gender norms without conforming to the norms applied to people of the opposite sex (which means taking steps to be perceived as a member of the opposite sex). Confounding accurate sex perception is demanding, and many people will not accept that demand. People $-50 \%$ of female people and $50 \%$ of male people, at the limit - should not have to undergo medical and surgical interventions with long-term health implications in order to eventually free themselves and others of oppressive gender norms. That would be too high a price to pay even if it were the only strategy available; and it isn't the only strategy available.

Assessing these internal costs, there seem to be good reasons not to take the transgender pathway. With the very small numbers who actually suffer gender dysphoria, it won't be efficacious; and with bigger numbers, it will be over-demanding. Furthermore, without sufficient legal protection of sex, the costs to women of sacrificing the legal protection of sex may be so high as to be a trumping concern.

\section{v. Tradeoffs between pathways}

I've already considered each pathway's internal tradeoffs. I said that there are no good reasons not to pursue the gender abolition pathway, some good reasons to be sceptical about the efficacy of the nonbinary and third gender pathways, and some good reasons not to pursue the transgender pathway. The third gender pathway and the nonbinary pathway (interpreted as a version of the gender abolition pathway) both come with the practical problem that if we can't successfully confound sex identification, and if binary gender norms don't turn into third gender norms along the pathways, then we'll end up in a world that is still marked by sex-based oppression.

This suggests a comparative ranking on which the transgender pathway should be the least preferred, with the gender abolition pathway most preferred. It is not clear how to rank the nonbinary against the third gender pathways (especially given that on one interpretation, the former collapses into the latter). But these conclusions are necessarily highly speculative, and depend on details about how gender norms might evolve and erode, and how their subjects might shift as we move along each pathway.

\section{Falling short of the limit cases, and hybrid pathways}

In the last section, I suggested four transitional pathways from the actual world to a world without sexbased oppression, and talked about tradeoffs between them. But it's not clear why we should assume that there's substantial uptake of one and only one pathway. So in this section I relax some of the simplifying assumptions that helped us to make progress in the last section (i.e. exclusive uptake of one pathway), and think about some of the interaction effects.

It might be that despite coming from different angles and having different commitments, the presence of trans, nonbinary, third gender, and norm-violating people all have the combined effect of challenging society's ideas about gender, in a way that has positive effects on those who are most constrained by gender roles.

The gender abolition pathway and the third gender pathway are good candidates for a hybrid pathway. ${ }^{18}$ At a certain point, when there are enough third gender categories and membership is entirely voluntary (at least when third gender norms have replaced binary gender norms), the third

\footnotetext{
18 On some readings, nonbinary is a third gender category (some nonbinary people report being sanctioned within their communities for not appearing androgynous enough). To the extent that's true, all three can be combined, in virtue of nonbinary being collapsed into third gender.
} 
gender world is actually gender abolitionist. We might still use the word 'gender', but the norms wouldn't be creating the problems they are today, especially for women. This hybrid pathway would combine the costs and the advantages of the two.

Whether the transgender pathway sits as easily with these two depends a lot on the difference between the limit case and all of the many steps along that pathway that involve smaller numbers of people. This means it's important to consider whether one male, or a small number of males, taking up the social position of women would create any of the same conflicts of interest that I mentioned already when discussing the limit case of that pathway.

For every case where gains for female people are zero-sum, there's a conflict. One male in a women-only sports team, one male in a women-only political party shortlist or serving as a political party's 'woman's officer', even one male as a keynote speaker at a women's film festival, one male 'lesbian' as an advisor to a major non-governmental LGBTQI+ charity, one male on the 'Top-100 Women in Business' list, one male in a women-only prison, one male in a women's shelter (there are real examples of all of these) makes a difference.

Having a women-only football team that has one male player and the rest female players is still better than having a women-only football team that has all male players, but even one male player means that one female player is missing out on a spot in that team. Males, unlike females, have not been historically excluded from or under-represented in football (and sports more generally, as well as politics, filmmaking, business. etc.).

This might also be true for cases where the gains for females are not so clearly zero-sum. For example, it is important for oppressed groups to have spaces of their own, to organize politically, and to experience solidarity with other members, and to simply have time that is free from interaction with members of the oppressor group and their socialized behaviours (for a discussion of this need in the context of people of colour needing spaces without white people, see Blackwell 2018; or watch the 2014 film and / or 2017 Netflix series Dear White People).

Olivia Blackwell gives the following as reasons for spaces free of white people:

\begin{abstract}
'We need places in which we can gather and be free from the mainstream stereotypes and marginalization that permeate every other societal space we occupy. We need spaces where we can be our authentic selves without white people's judgement and insecurity muzzling that expression. We need spaces where we can simply bewhere we can get off the treadmill of making white people comfortable and finally realize just how tired we are. [...] In integrated spaces, patterns of white dominance are inevitable. These patterns include things like being legitimized for using academic language, an expectation of "getting it right" (e.g. perfectionism), fear of open conflict, scapegoating those who cause discomfort, and a sense of urgency that takes precedence over inclusion. [...] These spaces aren't acts of oppression, but rather responses to it. They are our opportunity to be with each other away from the abuses of racism and patterns of white dominance' (Blackwell 2018).
\end{abstract}

Simply having one white person in a space like that can undermine the important gains to people of colour of having a space of their own, and likewise simply having one male in a women-only space can undermine the important gains to women of having a space of their own (on the parallels between race and gender transitioning see discussion in Tuvell 2017; see also discussion at Singal 2017).

So even when transition pathways are hybrid and partial, rather then singular and at the limit case, there is still reason to prefer the gender abolition and third gender pathways to the transgender pathway. If we are going to persist with the transgender pathway (in particular if we are going to move to an understanding of gender as identity that we wish to protect under the law) then it is imperative that we protect female people too, by clarifying the interaction between sex and gender (gender identity, gender reassignment, etc.) in law so that sex-based rights and protections remain sex-based, and by resisting the attempt by some gender identity activists to erase sex as a meaningful category (both socially and legally).

\title{
4. Conclusion
}

None of the pathways explored here should be reserved for people with gender dysphoria. People for whom the stakes aren't nearly so high should also consider taking on some of the social costs associated with the abolition or revision of gender norms and roles. The more flexibility there is around gender, the less pressure both male and female people will face in light of non-conformity, and the more that all of us will be free to do and be whatever we want to be. 
But the costs to each group of different ways of changing the world should be carefully assessed. Female people are still oppressed on the basis of their biological sex and should both have continued access to legal protection on that basis, and continued access to provisions to mitigate that oppression (without being expected to share these with other oppressed or disadvantaged groups).

Trans people still suffer high levels of harassment and discrimination and should have access to legal protection on that basis, and should be granted special provisions to mitigate any disadvantage (without that coming at a cost to other oppressed or disadvantaged groups - third spaces and antidiscrimination legislation are a way to accomplish this).

Biological females and trans people are both vulnerable groups (which partly overlap, by way of trans men), and both need to be protected along the way to achieving a world where gender isn't constraining for anyone. On these grounds, the exclusive pathways should be ranked from best to worst: gender abolition; third gender; nonbinary; transgender. The partial / hybrid pathways should be ranked from best to worst: gender abolition and third gender; transgender.

\section{Acknowledgements}

I'm grateful to audiences at the Australian National University, Victoria University of Wellington, University of Auckland, University of Flensburg, The University of York, and Lund University; and to Blake Hereth, Luke Roelofs, Robin Dembroff, Sophie Grace Chappell, Suzy Killmister, Charlie Montague, Louise Moody, Erin Nash, Sarah Fine, Will Tuckwell, Stephanie Collins, and Elinor Mason for helpful discussion, criticism, and/or written comments.

\section{References}

Allen, Sophie., Finneron-Burns, Elizabeth., Leng, Mary., Lawford-Smith, Holly., Jones, Jane Clare., Reilly-Cooper, Rebecca., \& Simpson, R.J. 'On an Alleged Case of Propaganda: Reply to McKinnon', manuscript, archived at philpapers.org 23rd September 2018.

Andelin, Helen. Fascinating Womanhood (New York: Random House, 1963).

Appiah, Anthony. "But would that still be me?" Notes on Gender, "Race", Ethnicity as Sources of "Identity", fournal of Philosophy 87/10 (1990), pp. 75-81.

Ásta. 'The Social Construction of Human Kinds', Hypatia 28/4 (2013), pp. 716-732.

Ásta. Categories We Live By (Oxford: Oxford University Press, 2019).

Asteriti, Alessandra., \& Bull, Rebecca. 'Gender Self-Declaration and Women's Rights: How Self-Identification Undermines Women's Rights And Will Lead To An Increase In Harms: A Reply to Alex Sharpe, 'Will Gender Self-Declaration Undermine Women's Rights and Lead To An Increase in Harms?’ Modern Law Review 83/3 (2020), \#539.

Atkinson, Ti-Grace. Amazon Odyssey (New York: Links Books, 1974).

Barnes, Elizabeth. 'Gender and Gender Terms', Nous 54/3 (2020), pp. 704-730.

Bettcher, Talia Mae. 'Trans Women and the Meaning of 'Woman', in A. Soble, N. Power, \& R. Halwani (Eds.) Philosophy of Sex: Contemporary Readings 6th Ed. (Maryland: Rowman \& Littlefield, 2013), pp. 233-250.

Bettcher, Talia Mae. 'Trans Identities and First-Person Authority', in Laurie Shrage (Ed.) You've Changed: Sex Reassignment and Personal Identity (Oxford: Oxford University Press, 2009).

Bicchieri, Christina. Norms in the Wild (Oxford: Oxford University Press, 2016).

Blackwell, Kelsey. 'Why People of Colour Need Spaces Without White People', The Arrowe, 9th August 2018. Online at https://arrow-journal.org/why-people-of-color-need-spaces-without-white-people/ accessed 26th September 2018.

Bogardus, Tomas. 'Evaluating Arguments for the Sex/Gender Distinction', Philosophia (2020) [early view].

Burt, Callie H. 'Scrutinizing the US Equality Act 2019: A Feminist Examination of Definitional Challenges \& Sociolegal Ramifications', Feminist Criminology 15/4 (2020) [early view].

Byrne, Alex. 'Are women adult human females?' Philosophical Studies, forthcoming.

Cox, Susan. 'Coming out as 'non-binary' throws other women under the bus', Feminist Current, 10th August 2016. Online at https://www.feministcurrent.com/2016/08/10/coming-non-binary-throws-women-bus/ accessed 10th September 2018. 
Crenshaw, Kimberle. 'Demarginalizing the Intersection of Race and Sex: A Black Feminist Critique of Antidiscrimination Doctrine, Feminist Theory and Antiracist Politics', University of Chicago Legal Forum 8/1 (1989), pp. 139-167.

Dembroff, Robin. 'Why be nonbinary?' Aeon, 30th October 2018. Online at https://aeon.co/essays/nonbinary-identity-is-aradical-stance-against-gender-segregation accessed 4th November 2018.

Equality and Human Rights Commission. 'Research Report 27: Trans Research Review', 7th October 2009. Online at https://www.equalityhumanrights.com/en/publication-download/research-report-27-trans-research-review accessed 5th November 2020.

Fine, Cordelia. Delusions of Gender (New York: Norton, 2010).

Fine, Cordelia. Testosterone Rex (New South Wales: Allen \& Unwin, 2017).

Finlayson, Lorna., Jenkins, Katharine., \& Worsdale, Rosie. “I'm not transphobic, but...”: A feminist case against the feminist case against trans inclusivity', Verso, 17th October 2018.

Firestone, Shulamith. The Dialectic of Sex (New York: William Morrow, 1970).

Frye, Marilyn. The Politics of Reality (New York: Crossing Press, 1983).

Haslanger, Sally. 'Gender and Race: (What) Are They? (What) Do We Want Them To Be?' in Resisting Reality (Oxford: Oxford University Press, 2012), pp. 221-247.

Jenkins, Katharine. 'Amelioration and Inclusion: Gender Identity and the Concept of Woman', Ethics 126/2 (2916), pp. 394421.

Jenkins, Katharine. 'Toward an Account of Gender Identity', Ergo 5/21 (2018), pp. 713-744.

Koyama, Emi. 'The Transfeminist Manifesto', in Rory Dicker \& Alison Piepmeier (Eds.) Catching a Wave: Reclaiming Feminism for the Twenty-First Century (Northeastern University Press, 2003).

Lawford-Smith, Holly. 'If anyone can choose to be female, what happens to women's rights?' The Australian, February 27th $2019 a$.

Lawford-Smith, Holly. 'Implications of sex-change act amendment have not been fully explored', The Age, 6th July $2019 b$.

Lawford-Smith, Holly. 'Why some feminists oppose allowing people to choose their sex on birth certificates', The Conversation, 23rd August 2019.

Long Chu, Andrea., \& Berg, Anastasia. 'Wanting Bad Things', The Point, 2018. Online at https://thepointmag.com/2018/dialogue/wanting-bad-things-andrea-long-chu-responds-amia-srinivasan accessed 6th September 2018.

MacKinnon, Catharine. Feminism Unmodified (Massachusetts: Harvard University Press, 1987).

Manne, Kate. Down Girl: The Logic of Misogyny (Oxford: Oxford University Press, 2017).

McKitrick, Jennifer. 'A dispositional account of gender', Philosophical Studies 172/10 (2015), pp. 2575-2589.

Murray, Kath., \& Hunter-Blackburn, Lucy. 'Losing sight of women's rights: the unregulated introduction of gender selfidentification as a case study of policy capture in Scotland', Scottish Affairs 28/3 (2019), pp. 262-289.

Neuffer, Julie Debra. Helen Andelin and the Fascinating Womanhood Movement (Utah: University of Utah Press, 2015).

Nussbaum, Martha. Creating Capabilities (Cambridge, MA: Harvard University Press, 2011).

Nussbaum, Martha. Women and Human Development: The Capabilities Approach (Cambridge: Cambridge University Press, 2000).

Pandian, Sharad. 'Whipping Girl: A Transsexual Woman on Sexism and the Scapegoating of Femininity', GoodReads, 25th June 2018. Online at https://www.goodreads.com/review/show/2435403536 accessed 10th September 2018.

Raymond, Janice. The Transsexual Empire (Boston: Beacon Press, 1979).

Reilly-Cooper, Rebecca. 'Equality for trans people must not come at the expense of women's safety', politics.co.uk, 26th January 2016a. Online at http://www.politics.co.uk/comment-analysis/2016/01/26/equality-for-trans-people-must-not-come-atthe-expense-of-wo accessed 6th September 2018. 
Reilly-Cooper, Rebecca. 'Gender is not a spectrum', Aeon, 28th June 2016b. Online at https://aeon.co/essays/the-idea-thatgender-is-a-spectrum-is-a-new-gender-prison accessed 4th October 2018.

Serano, Julia. Whipping Girl: A Transsexual Woman on Sexism and the Scapegoating of Femininity (Berkeley: Seal Press, 2007).

Skylar. 'No, coming out at non-binary does not throw other women under the bus', itequals.com, 2nd December 2016. Online at http://itequals.com/gender/no-coming-out-as-non-binary-does-not-throw-women-under-the-bus/ accessed 10th September 2018.

Smith, Laura. 'This book is the marriage bible for 'alt-right' women, and it was written in 1963', Timeline, 18th August 2017. Online at https://timeline.com/fascinating-womanhood-andelin-feminism-509dfe538de7 accessed 25th September.

Stock, Kathleen. 'Not the Social Kind: anti-naturalist mistakes in the philosophical history of womanhood', manuscript, as at 24th February 2020. Online at https://philpapers.org/rec/STONTS

Stock, Kathleen. 'Why self-identification should not legally make you a woman', The Conversation, 1st October $2018 a$.

Stock, Kathleen. 'Changing the concept of woman will cause unintended harms', The Economist, 6th July $2018 b$.

Singal, Jesse. 'This is What a Modern-Day Witch Hunt Looks Like', Daily Intelligencer, 2nd May 2017. Online at http://nymag.com/daily/intelligencer/2017/05/transracialism-article-controversy.html accessed 26th September 2018.

The Feminists. 'The Feminists: A Political Organization To Annihilate Sex Roles', in Anne Koedt, Ellen Levine, \& Anita Rapone (Eds.) Radical Feminism (New York: Quadrangle, 1973), pp. 368-378.

Tuvel, Rebecca. 'In Defence of Transracialism', Hypatia 32/2 (2017), pp. 263-278.

Valentini, Laura. 'Ideal Vs. Non-Ideal Theory: A Conceptual Map', Philosophy Compass 7/9 (2012), pp. 654-664.

Witt, Charlotte. The Metaphysics of Gender (USA: Oxford University Press, 2011). 